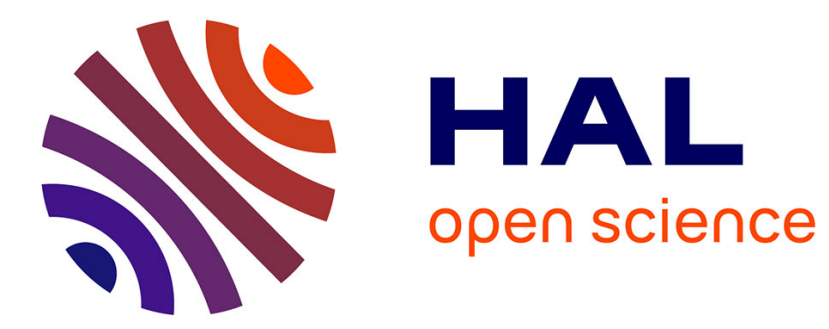

\title{
Ethical Perspectives on Synthetic Biology
}

Bernadette Bensaude-Vincent

\section{To cite this version:}

Bernadette Bensaude-Vincent. Ethical Perspectives on Synthetic Biology. Biological Theory, 2013, 8 (4), pp.368-375. hal-00937211

\section{HAL Id: hal-00937211 \\ https://hal-paris1.archives-ouvertes.fr/hal-00937211}

Submitted on 28 Jan 2014

HAL is a multi-disciplinary open access archive for the deposit and dissemination of scientific research documents, whether they are published or not. The documents may come from teaching and research institutions in France or abroad, or from public or private research centers.
L'archive ouverte pluridisciplinaire HAL, est destinée au dépôt et à la diffusion de documents scientifiques de niveau recherche, publiés ou non, émanant des établissements d'enseignement et de recherche français ou étrangers, des laboratoires publics ou privés. 
Bernadette Bensaude Vincent

Ethical Perspectives on Synthetic Biology

Biological Theory. 8 [4] 2013: 368-375 [Thematic Issue Article:

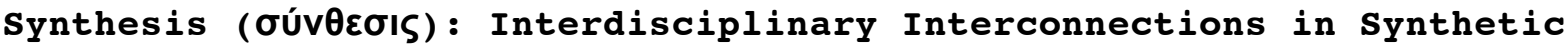
Biology ]

Received: 1 March 2013 / Accepted: 4 August 2013

\title{
B. Bensaude Vincent
}

Université Paris 1-Panthéon-Sorbonne, Paris, France

e-mail: Bernadette.bensaude-vincent@univ-paris1.fr

\begin{abstract}
Synthetic biologists are extremely concerned with responsible research and innovation. This paper critically assesses their culture of responsibility. Their notion of responsibility has been so far focused on the identification of risks, and in their prudential attitude synthetic biologists consider that the major risks can be prevented with technological solutions. Therefore they are globally opposed to public interference or political regulations and tend to self-regulate by bringing a few social scientists or ethicists on board. This article emphasizes that ethics lies beyond
\end{abstract}


prudence and requires a cultural evaluation of the modes of existence of the various microorganisms designed by synthetic biologists, independently of their potential applications.

\section{Keywords}

Anthropocentrism - Design - Prudence - Public engagement - Risks Self-regulation

It is now well established that the emergence of novel technologies such as nanotechnology, genomics, or synthetic biology raises ethical issues. As these technologies reengineer life and promise revolutionary applications, they also generate concerns and risks that have to be addressed upstream. Ethics is viewed as the ordinary companion of science and technology in contemporary risk societies (Beck 1992). From the beginning, publicly funded research programs on synthetic biology have devoted a portion of their budgets to the study of potential ethical, legal, and societal impacts. The European EC-FP6 program funded SYNBIOSAFE, a project focused on the safety, security, and ethical aspects of synthetic biology (Schmidt et al. 2009). In the USA, the Synthetic Biology Engineering Research Center (SynBERC) brought together biologists, engineers, and humanities scholars to achieve its ambition of "making life easier to engineer." The community of synthetic biologists seems to be concerned with their responsibility as scientists. The international meetings launched in 2004 by the Biobricks Foundation include talks or even symposia on ethical and societal issues with the intention to "work together so that the ramifications of such efforts are most 
likely to benefit all people and the planet"

(http://sb6.biobricks.org/about/). Although "profit" is not mentioned, it is clear that synthetic biology is part of the general commitment to "responsible research and innovation" that has been epitomized by three "P"s in a report to the European Commission: “Responsible Research and Innovation as an outcome seeks to generate the 'right' end points which benefit people, planet and profit" (Sutcliffe 2011, p. 7).

What is the outcome of ten years of buzz and concern about responsibility in synthetic biology? What are the measures to regulate the development of synthetic life, to prevent potential disasters, and to engage the public in technological choices? An overall survey of what has been done over the past decade is much needed but it would be beyond the scope of this article. Its ambition is more modest. It first considers the purposes and commitments to responsible behavior in various reports and initiatives in Europe and the USA. The second section tries to clarify what responsibility means for synthetic biologists, policy makers, industrial managers, and civic associations. The third section will emphasize the limitations of current ethical perspectives. Finally the article broadens the spectrum of ethical issues that remain to be addressed and discussed in a public arena.

\section{$<A>$ Will to Responsibility $<A>$}

Synthetic biology is a heterogeneous field with a variety of research agendas and visions of the future (Deplazes 2009). The modular approach of the Biobricks program differs from metabolic 
engineering, from the minimal genome approach, from in silico synthesis or computer modeling, and finally from the chemical synthesis of protocells. In turn they seem quite far from the ambitions of xenobiology aimed at the synthesis of alternative nucleic acids. It therefore comes as no surprise that synthetic biologists develop quite different views about their responsibility. Also, not all countries are equally engaged in synthetic biology research and the accompanying programs about ethical, legal, and societal impacts (ELSI). In Europe, a comparative study shows that such programs are well funded and developed in the United Kingdom, while there is no real effort on ELSI issues in Switzerland and Netherlands (Pei et al. 2010). Even in the UK, ethical and societal issues are not the prime concern. In stark contrast to the 2004 report on nanotechnology by the Royal Society and the Royal Academy of Engineering (RAENG), which balanced challenges and opportunities, the report on synthetic biology published by the latter in 2009 is primarily focused on the potential competitive advantages generated by synthetic biology for the UK (RAENG 2009).

In France, the Parliamentary Office for the Evaluation of Scientific and Technological Choices (OPECST) published a report in 2012 assessing the main ethical, economic, and social challenges of synthetic biology (Fioraso 2012). However, no concrete initiative came to match the national ambitions (Meyer 2013), apart from the creation of an observatory of synthetic biology, which is in charge of a bioforum, a series of stakeholders debates to be held in 20132014 .

Science policy makers are obviously concerned although they are not presenting a wide range of proactive initiatives. The European Union launched a two-year project, Synbiosafe (2006-2008), which did 
a very good job of identifying issues related to the method, applications, and distribution of synthetic biology. As it is assumed that synthetic biology does not raise novel ethical issues, the program resulted in a kind of checklist of standard issues such as biosafety, biosecurity, intellectual property, and social justice (Schmidt et al. 2009). This checklist of issues was later developed by the European Group on Ethics in Science and New Technologies to the European Commission (EGE) who “agreed that apart from safety issues associated with synthetic biology, an ethical, legal and political governance of synthetic biology is needed in the EU and worldwide to ensure that the interests of society are respected" (EGE 2011).

Who is in a position to clarify the interests of society? Over the past decade scientific journals have published many articles and special issues related to synthetic biology with occasional commentaries about ethical issues. However, the buzz about synthetic biology has not really penetrated the public sphere. Despite spectacular announcements and a number of articles on biohackers, the media coverage for synthetic biology has been rather modest. In 2010 a survey commissioned by the European Commission concluded that $17 \%$ of the European public is aware of the existence of synthetic biology (European Union 2010).

Does this mean that there is no concern at all in the civil society? The Canadian activist nongovernmental organization (NGO) ETC Group issued three alarming reports on synthetic biology calling for a moratorium (ETC Group 2007, 2008, 2010). Nevertheless, over the first decade, synthetic biology prompted very few public debates or citizen conferences. Apart from the citizen juries organized in the UK and a 6-month public forum organized by the French civil 
society organization VivAgora in 2009, the subject is rarely brought into the public arena. There is no real dialogue with the society at large. Listening to the public might well slow down the pace of development that synthetic biologists want to maintain or accelerate. The conclusions of a public dialogue conducted in the UK together with 41 stakeholder interviews show that the promises of smart solutions to big issues such as renewable energy or medicines are not convincing enough to overcome all concerns. Significantly, the most serious concerns expressed in this dialogue are related to the motivations of scientists who, driven by their own research interests, might forget their responsibility (Bhattachary et al. $2010)$.

Nevertheless, the champions of synthetic biology in the USA did not forget their responsibility. They strive to behave as responsible engineers with regards to the products of their activity. In the series of international conferences synthetic Biology x.0 organized by the Biobricks Foundation, ethical issues are an integral part of the programs. The first meeting in June 2004 closed with a plenary lecture delivered by Paul Rabinow, a famous anthropologist at Berkeley (Rabinow 2004). The second meeting, held at Berkeley in 2006, dedicated a third day to four key societal issues: biosecurity and risks, public understanding and perception, ownership and sharing, and community organization. The third conference in Zurich had a few parallel sessions on ethics. At the Synthetic Biology 4.0 meeting in Hong Kong (2008), ETC Group hosted a panel session on global societal impacts. At the same time the gene companies grouped in an International Association of Synthetic Biology started negotiations to set up a universal code of conduct for screening orders (Maurer 2009). At Synthetic Biology 5.0 at 
Stanford in July 2011, a poster session was arranged on "interacting with the world" (including risks, environmental, ethical, legal, societal, and philosophical issues). And SB 6.0, held at Imperial College in London in July 2013, called for papers on environmental and societal issues. This thematic organization emphasizes the concern with broader societal issues, and at the same time is reminiscent of the old divide between humanities and natural sciences .

Thorough attempts at moving beyond the too famous divide between the two cultures are nevertheless noticeable. Social scientists have been invited to work closely with synthetic biologists, on a daily basis. In a number of research projects, humanity scholars have been "embedded." For instance, the Paris Team in the 2009 iGEM competition was awarded a prize for the ethical and sociological analysis included in the project (Aguiton 2009). However, the junior scholar who was publicly celebrated during the jamboree in Boston had been in agony during the six previous months spent on the research team. She had been ignored, ostracized by the young science students who worked enthusiastically to prepare their biological part for the international competition. A more substantial commitment to ethics was the appointment of two senior anthropologists in the program of the consortium SYNBERC in 2006. A permanent section entitled "Human Practices" headed by Paul Rabinow and Gaymon Bennett was created and generously funded. The two social scientists were to follow the local daily research pathway of synthetic biologists. They deliberately discarded the conventional position of bioethicists speaking from an outsider's perspective and made efforts to calibrate ethics to the actual research conducted in the consortium rather than to what was imagined or promised. They 
consequently determined to observe the researchers, to participate in the weekly laboratory meetings rather than taking the futuristic visions developed in public discourses. However, this attempt at integrating ethics as a major component of research projects endedin 2012 as the protagonists failed to engage in collaboration. This "anthropological experiment"--as Rabinow and Bennet name it--has been rejected by the leaders of the project (Rabinow and Bennet 2012 ). In Year 5 of the project the Human Practices division was accused of doing only observation. Rabinow and Bennet were criticized and resigned. The division is now reconfigured as "Practices" and focused on issues of risks. Ethicists on board had to comply with the expectation of the synthetic biologists rather than developing their own research interests. This quick survey of various sites where ethical issues about synthetic biology are addressed suggests that ethics has been dominated by synthetic biologists who frame the relevant issues and hire social scientists to support and secure the advancement of their research projects. Despite the European urging for a multistakeholder governance, despite the strong recommendations of the SYNbiosafe project, few citizens have been engaged in a dialogue and public interventions are not welcome. Synthetic biology revives the ideal of self-regulation discussed in the early time of genetic engineering, at the Asilomar Conference in 1975 (Cameron and Caplan $2009)$.

\section{$<$ A $>$ How Has Responsibility Been Framed? $<$ A $>$}

In their effort to pursue the Asilomar ideal of self-regulation, the community of the Biobricks Foundation has developed an ethos based 
on openness and transparency. They invite amateurs' practice and promote garage or DIY biology. They encourage young talents to participate in the construction of the Registry of Standardized Bioparts through the international annual competition iGEM. In thus challenging the established hierarchies of academics, they champion a democratization of scientific practice. They promote a new model of scientific sociability open to amateurs, based on enthusiasm and creativity

In addition, they are opposed to the regime of intellectual property in biotechnology and are working hard to initiate a regime of open biology, inspired by the movement of open access in computer engineering (Calvert 2012; Hilgartner 2012). The Biobricks Foundation has implemented a legal framework to ensure free and open access to the standard Biobricks collected at the MIT Repository of Standard Biological Parts. The aim is to develop open technical standards to characterize the Biobricks and to provide educational support to allow the public to use and improve the Biobricks. Sharing information and materials is viewed as a precondition for the success of synthetic biology because patents increase the costs of research to such a point that they become an obstacle to further developments. For Rob Carlson, the open source paradigm is necessary for a rapid increase of users of synthetic biology that will bring cost reduction and secure the commercial future of synthetic biology (Carlson 2010). Carlson's plea for open source is not based on moral injunctions; rather, it goes hand in hand with epistemological and political recommendations. Carlson favors the strategy of chassis over synthetic genomics as the most promising approach because it reduces complexity (Carlson 2010, p. 102). Accelerating innovation in biotechnology requires molecules that behave in understandable 
and predictable ways, for simulation and standardization purposes. Along with his epistemological choice of reductionism, Carlson presents the political options required for the successful development of synthetic biology. He vehemently advocates a free and deregulated market for synthetic biology, arguing that regulations are always leaky and inefficient. He refers to the ban on illicit drugs and concludes that "where there is a market, there will always be attempts to supply it" (Carlson 2010, p. 123).

From the moral notion of responsibility, which implies obligations and the commitment to respond for one's actions, what is retained? Since "ethical responses do not pre-exist the questions that elicit them" (Dupuy and Grinbaum 2004), what are the questions that prompt ethical concerns among synthetic biologists? The ethical debates in the series of SB conferences are essentially about risk issues. From the outset, biosecurity came up as the major concern: as synthetic biology can synthesize pathogen viruses it can be misused to make more effective bioweapons. The risk of bioterrorism is enhanced since artificial DNA can be purchased on the Internet. Stephen Maurer, a lawyer at Berkeley, outlined a code of conduct for protecting the public from the risks of bioterrorism, which relied on the capacity of gene companies to screen orders and on the scientific will and commitment for the field to regulate itself. This proposal raised controversy and 35 NGOs including ETC Group, GeneWatch, and Greenpeace, protested and urged to open a public debate on synthetic biology (Aldhous 2006).

Biosafety is also a major concern. Significantly, in Europe the ethical agenda of synthetic biology has been set up in the program entitled SYNbiosafe. Although the outline of the project distinguished three categories of issues--method-related, 
application-related, and distribution related (Desplazes et al 2009)--there is a striking imbalance in the treatment of each category. Application-related issues have attracted most of the attention. The ethical awareness is most often limited to risk issues, thus reducing ethics to a form of prudence. ${ }^{1}$ Thus the culture of responsibility developed in the synbio community is more or less reduced to accountability. This term derived from book keeping denotes impersonal numbers, standardized rules, and procedures. In most countries, ethical discussions on synthetic biology revolve around risk issues and result in a list of standard issues to be addressed: biosecurity, biosafety, biohacking, intellectual property, and social justice. It is more or less the same checklist, which came from the programs dedicated to ELSI in nanotechnology. The mission of ELSI researchers is primarily to identify and clearly articulate a number of major issues raised by the development and diffusion of the emerging technology. And just as for nanoparticles, the discussions about the risks associated with synthetic biology center on the question: to what extent is it different from other biotechnologies? The risk issue inevitably shifts toward the question of novelty, which prompts two kinds of attitudes: the promoters of the emerging discipline are fond of revolutionary claims while people working for industrial companies rather emphasize continuity in order to reassure the public. On the one hand, Drew Endy and Rob Carlson claim the radical novelty of synthetic biology as they describe the current state of bioengineering as a modest bricolage. This unreliable tinkering with genes will be overcome by the more professional practices of the

\footnotetext{
${ }^{1}$ In his lectures at Stanford University, the French philosopher Jean-Pierre Dupuy occasionally compares the confusion between ethics and prudence to the mistake of a physics student who would not make the distinction between weight and mass.
} 
Biobricks program based on the solid foundations of standardization, decoupling, abstraction ${ }^{2}$. On the other hand, when it comes to regulating industrial production, the Biotechnology Industry Organization (BIO) in Washington DC clearly states that there is nothing new or special about synthetic biology: “In our view, synthetic biology is an extension of the continuum of genetic science that has been used safely for more than 40 years by the biotechnology industry in development of commercial products" (Eickson et al. 2011).

The kind of ethical research encouraged by synthetic biologists consists of prospective exercises meant to anticipate potential adverse effects. Ethics is focused on the identification of risks, and those risks are immediately balanced with the huge potential of benefits expected from the future applications of synthetic biology. Anticipating risks and making efforts to prevent them is considered as the ultimate responsible attitude. It means that the kind of ethics required by the proponents of synthetic biology has little in common with professional ethics. It is closer to the professional obligations of managers, including risk assessment, prospective studies and measures of prevention. Anticipating and preventing adverse effects is a managerial attitude. Synthetic biologists should go ahead and include upstream technical solutions to prevent potential risks. For preventing the dissemination of synthetic organisms and the risks of contamination of natural life, synthetic biologists demonstrate their prudence in suggesting novel forms of containment: in addition to the conventional measures of containment in laboratories, they plan to design synthetic microorganisms

\footnotetext{
${ }^{2}$ However, it is worth mentioning that some synthetic biologists consider the Biobricks program more as a tool to bring students in contact with the field, through the iGEM competition, rather than as a serious program of engineering.
} 
dependent on a specific artificial nutriment that cannot be found in nature. A third measure to prevent interplays with the environment is to engineer organisms with a genetic code that is not readable by ordinary DNA-based organisms. Thus, the attempts at synthesizing unnatural nucleic acids such as XNA are being justified as measures of prudence (Schmidt and Lorenzo 2012).

Finally, issues of social justice have been so far addressed in terms of access to and distribution of synthetic biology resources. It is all about enabling innovative developments of synthetic biology through open access and preventing the enhancement of the global divide through an international dialogue. Never is there a hint that synthetic biology and other so called "technological fixes" could be one more alibi to avoid facing the world we have made through previous generations of technology. Rather than confront the underlying problems of over-consumption and waste, synthetic biology is promoted as a "remediation"--a means to "medicate" a solution for the earth.

\section{<A>Beyond Risks and Impacts, what Kind of Governance<A $>$}

Therefore, the kind of responsibility developed in an ELSI framework can hardly be considered as a true ethical attitude. It certainly fits in ethical theories that judge the rightness of actions based on the intentions of the moral agents. But good intentions do not guarantee responsible behavior. "Responsible scientists" motivated by the best intentions in the world might unwittingly turn into irresponsible citizens who shape unsustainable futures. 
Although anticipating impacts is looking at the consequences of actions, ELSI research cannot be considered as an instantiation of consequentialism. This specific ethical theory judging the wrongness and the rightness of actions on the basis of their consequences (rather than on the intentions of the agent or the action itself) would require taking into account the contingency of the future. Instead of making decisions on the basis of calculable risks, a consequentialist has to take into account what we do not know, i.e., the ignorance generated by increasing knowledge, the scientific uncertainty embedded in synthetic biology. In consequentialism, the responsibility for the consequences has to be extended to the realm of "moral luck" when the course of the action to be judged depends on factors beyond the control of the moral agent (Williams 1981). The major limitation of the programs of anticipatory governance of risks in synthetic biology is that they simply overlook or even deny uncertainty. They rest on a blind adhesion to the reductionist manifesto of the Biobricks Foundation, assuming that human-designed, standardized, and well-characterized biological parts assembled into modules will be entirely predictable and that the synthetic organism will not have any emergent properties. Despite the doubts about the feasibility of this program, despite repeated attempts by experts to emphasize the radical uncertainty lying in synthetic biology (Rodemeyer 2009 ;)ethical and regulatory measures still rest on overconfidence in the control of synthetic microorganisms and deal almost exclusively with risks. In particular, the 2011 report of "BIOS," the research program conducted by the Centre for synthetic Biology Innovation at Imperial College on synthetic biology, refers to Sheila Jasanoff's notion of "technology of hubris" to characterize the over-reliance on scientific evidence and 
systematically downplays the uncertainties (Jasanoff 2003; Zhang et al. 2011, p. 16). The authors of the report propose to move from "scientifically informed bureaucracy" to "artistic governance." In the face of scientific uncertainty, in the face of the variety of actors involved in synthetic biology and the variety of scientific, industrial, and geopolitic interests at stake, the most effective governance consists in a continuous provocation of reflexivity among stakeholders rather than in a rigid regulatory regime.

Thus self-regulation, risk assessment and evidence-based policy have shown their limits. It is time to counterbalance the temptation to leave the governance of synthetic biology to a few dozen experts and let them decide if and how it should be regulated.

\section{$<$ A $>$ Of Microbes and Men $<$ A $>$}

If we are to open up the field instead of closing it up on risk issues, and to develop an "art of governance," on which basis can we appraise synthetic biology? First of all, it is important to try to disentangle the valuations underlying the design of biological artifacts, to clarify them in order to submit them to open debates. Anticipating the impacts that could be made by the products of genetic engineering is certainly a useful and proactive attitude. But the process of design in itself is value sensitive, especially when it comes to designing life.

Whatever the purposes of their designers, anthropological meanings are embedded in biological artifacts together with deep cultural, albeit tacit, valuations. Using John Dewey's conceptual distinction between valuations and evaluations (Dewey 1939; Bensaude 
Vincent and Nurock 2010), this section aims to clarify the spontaneous and intuitive assessments (valuations) in order to foster reflexive judgments (evaluations).

For this purpose, it seems better to proceed bottom-up, from the objects designed in synthetic biology up to their moral significance, rather than top-down from the perspectives of ethical doctrines. In liberal states, the governance of synthetic biology cannot be built on the basis of a privileged moral doctrine. Moral choices belong to the private sphere and cannot determine public or legal actions, whereas the government is expected to engage in the defense of core moral views such as humanity and nature.

Even though Rabinow and Bennet failed to convince their scientific partners that they had to collaborate in order to construct an appropriate ethical framework, their central question remains to be addressed: to what extent do the objects designed by synthetic biologists question the definition of what it means to be human? Synthetic biologists create new objects, they refurbish the world with human-designed entities that are supposed to perform desired functions and self-reproduce without interfering with their environment. The mode of existence of the objects designed in synthetic biology laboratories at the borderline between the natural and the artificial, between the living and the non-living, inevitably questions the grand divides that are the backbones of modern Western culture. They raise issues about the place and role of humans in nature, their relations to animal life, and to the environment in general.

The cultural evaluation of such value-sensitive objects of design cannot be conducted on synthetic biology in general. Distinctions have to be made between the various kinds of objects 
designed under the umbrella of synthetic biology. Such distinctions should not be based primarily on the potential adverse effects that synthetic organisms could have-risk issues are only a minor component of the defense of core values--but will rather be based on their modes of existence.

Are biosynthetic objects natural or artificial? In "essence" synthetic biology is about redesigning and reengineering life. Its products are hybrids of natural objects and artifacts. But all products of human technology are also hybrids, as Descartes already argued against the ontological divide maintained by scholastic philosophers between nature and artifice ${ }^{3}$ Like Descartes, and his contemporaries, synthetic biologists value the products of their design for two major reasons: artifacts are useful for cognitive purposes as well as for increasing human health and wealth. Their insistence on quoting Richard Feynman's alleged saying--"What I cannot create I do not understand"--or Steven Benner's emphasis on synthesis as being the best way to test hypotheses (Benner et al. 2011 ) suggests that knowing through making is a major justification of synthetic biology. Social utility is even more valued, at least in the public discourses promising environmental and heath benefits. It thus seems that the ambition to design and control living organisms is in keeping with the humanistic ideal of modernity. Synthetic biologists still consider it their duty "de se rendre comme mâtre et possesseur de la nature," to place humans above all other animal species. They feel free to use living beings (whether

\footnotetext{
${ }^{3}$ Descartes: "I don't recognize any difference between artefacts and natural bodies except that artefacts mostly work through mechanisms that are big enough to be easily perceivable by the senses (they have to be, if humans are to be able to manufacture them!)" (Principles of Philosophy, 1644, Section 4, § 203).
} 
plants or animals) in their service. ${ }^{4}$ Synthetic biology is thus

valued as the continuation of the long-term process of emancipation from nature, equaled with civilization. Far from being a philosophical watershed, it reaffirms that humans are in command of nature. This anthropocentric perspective justifies the serene response of the Vatican to Craig Venter's announcement of the creation of a synthetic bacterium. As long as synthetic biology is not creating life de novo, and is working for the benefit of humanity, anthropocentric ethics is safe.

However this anthropocentric perspective can be challenged from two alternative perspectives: Is it possible to countervalue synthetic organisms as "works," as products of engineering? Is it possible to countervalue them as living beings?

While nature remains a core value in our culture, artifacts also have their cultural dignity. They can be valued either as expressions of human creativity or as technical objects operating and enduring in the world. Do synthetic biologists praise technology? A striking feature of Craig Venter's public presentation of his synthetic bacteria significantly named Mycoplasma laboratorium in 2010 is that he did not say a word about the engineering skills and the tour de force needed to implement a synthetic genome into the cell machinery of a neighboring Mycoplasma. Far from valuing the technicalities of this achievement he claimed: "This is the first self-replicating cell we've had on the planet whose parent is a computer" (USA Today 5/20/2010). Digital culture and design seem more highly valued among synthetic

\footnotetext{
${ }^{4}$ This underlying valuation has been the target of an artist's criticism through an extreme-art project. The exhibit Synth-Ethic in Vienna displayed "le cheval en moi" by Marion Laval-Jeautet who has been injected with horse immunoglobin for several months and gradually developed tolerance to the point of accepting a transfusion of horse blood. She claims that animal is the future of humans.
} 
biologists than technicality. Technicality as a mode of existence has been highly valued by the French philosopher Gilbert Simondon. In his view, a concrete technical object is not the implementation of a design project into the physical world. Nor is it the assembly of individual parts with each part performing a specific function. Such abstract and "hypertelic" constructions signal artificiality rather than technicality (Simondon 1989, p. 47). By contrast, technical objects come into existence through a process of individuation, including the "milieu" into their operating scheme, just as natural objects. The process of individuation is neither the juxtaposition of fixed individual functions, nor a subjection of nature to human interests. Are there any hints of valuation of technicality in synthetic biology? Clearly the objects designed in the Biobricks program are all but concrete technical objects (Kogge and Richter 2013). They are only individual parts, designed for performing a specific function waiting to be assembled in modules, that will still remain parts because no concrete entity can result from this process of Lego construction. As objects modeled on software engineering they are algorithmic machines rather than individual objects analogous to natural objects.

The objects designed in the branch known as xenobiology are presented as unnatural or "orthogonal" even when they are designed as "analogs" of natural nucleic acids. Most of them are abstract objects--in Simondon's sense--because they are designed for avoiding interactions with natural DNA in order to prevent risks (Marlière 2009). Like soil-less cultures they are designed to operate offground, independently from the cell's natural environment. They are deprived of autonomy, and of the mobility and capacity to enter into new associations with their "milieu". As products of human design, 
they are neither the outcomes of contingent history like living beings, nor the outcomes of a process of individuation as concrete technical objects. They ignore the interdependency of individuals with their environment as well as the interdependency of present, past, and future, which characterize the mode of existence of natural and technical objects. As long as containment is the major concern of synthetic biologists, the problem of coexistence and synergies between synthetic organisms and natural organisms, which have acquired evolutionary capacities through billions of years, cannot be addressed. Therefore, such biosynthetic objects share no community of interests with living beings. There is no way for them to participate in a common world. They are from nowhere, from no time. They belong to the kingdom of utopia and uchronia but they do not acquire the cultural dignity of technical objects.

What about yeasts and bacteria engineered or reengineered for synthesizing precursors of drugs or of biofuels? They only exist as instruments of production in a laboratory or a factory. They are production tools confined in spaces under control, as generations of microorganisms have been used in the manufacture of beer, wine, yoghurts over the past centuries. They have to be stabilized and standardized for entering into large-scale industrial production. From a biocentric perspective is it right to conceive living entities as machines performing functions for humans, to reduce them to chassis that can be functionalized in our service? Whatever their degree of artificiality synthetic organisms are living beings. As such they have an intrinsic value. For instance, the oncomouse designed in a Harvard laboratory for use as a research tool, which became a patentable invention and a commercial entity, has been depicted by Donna Haraway as a mouse that suffers so that we may 
live (Haraway 1997). This transgenic and human-designed object nevertheless raises compassion and solidarity.

Indeed, the organisms engineered by synthetic biologists are not like suffering animals. They are hardly considered as living beings deserving our respect. As heirs of two centuries of hygienist medicine even biocentric ethicists are more inclined to consider microbes as enemies rather than as moral subjects. Yet this spontaneous valuation may quickly change if we consider with the symbiotic relations between microbes and men. The thousand different species of commensal microorganisms associated with human bodies which form a complex ecosystem are highly valued by synthetic biologists who consider that thanks to their social interactions these microbes could be excellent vectors for deploying synthetic genetic circuits (Warren et al. 2011). If we accept that we are in a relation of mutual dependence with microbes we can no longer deal with them as simple means towards our ends. They rather can be seen as co-operators. Even though they may not suffer and raise empathy, they deserve care and assistance like domesticated animals, which have shared human lives through many centuries.

More precisely, it is the reductionist concept of life underlying the project of designing synthetic organisms that is questionable from an ethical perspective. The Biobricks program, for instance, is typically framed along a Cartesian view. Living systems are made of functional parts that can be assembled into a machine like a watch. This mechanistic concept of life supports a project of exploitation. As George Canguilhem convincingly argued, the Cartesian theory of animals-machines conveniently supported the project of using them as machines in the service of men (Canguilhem 1971). In stark contrast, Kant's comparison between mechanical 
machines (watch) and organic bodies (tree) emphasized the distinctive value of organized bodies. Unlike mechanical machines which have a "motive power," organisms have a "formative power." They self-reproduce, they maintain themselves. Their parts exist in relation to each other and to the whole, they are not designed by a clockmaker in accordance with a project. In this view living entities are an end in themselves and should not be used as machinetools for heteronomous ends.

In conclusion, it is clear that the "responsibility" promoted by the synthetic biology community is far from satisfactory for addressing the ethical issues raised by this emerging technology. Without questioning the good intentions of synthetic biologists, the strategies developed to address ethical issues suggest a strong rejection of public interference or intervention in their turf. Moreover, the focus on risk issues encourage the belief that societal and environmental problems are amenable to technological solutions. The governance of uncertainties requires broadening the interface between scientists working in the field of synthetic biology and the civil society. If the objects designed by synthetic biologists are to be parts of our common world, they have to be evaluated from an ethical and a political perspective.

\section{References}

Aldhous P (2006) Synthetic biologists reject controversial guidelines. New Scientist, May 23, http://www.newscientist.com/article/dn9211

Aguiton S (2009) SynthEthics: an ethical and sociological analysis on synthetic biology. Report presented at the 2009 iGEM competition 
for the award "Human Practices Advance"

http://www.cso.edu/cv_equipe.asp?per_id=164

Beck U (1992) Risk society: towards a new modernity. Sage, New Delhi. Bensaude Vincent B, Nurock V (2010) Ethique des nanotechnologies. In: Emmanuel Hirsch (ed) Traité de bioéthique, vol. 1, Paris, Érès, pp $355-369$

Bhattachary D, Pascall J, Hunter A (2010) Synthetic biology dialogue. Report of the BBSRC and EPSRC <AQ: please spell out; complete reference; publisher? place?>

http://www.bbsrc.ac.uk/syntheticbiologydialogue/. Accessed 11 Feb 2013

Bontems V (2013) Esclaves et machines, meme combat! L'aliénation selon Marx et Simondon. Cahiers Simondon no. 5, Barthélémy JH (ed), L'Harmattan, Paris

Calvert J (2012) Ownership and sharing in synthetic biology: a 'diverse ecology' of the open and the proprietary? BioSocieties $7: 169-187$ Cameron N, Caplan A (2009) Our synthetic future. Nature Biotechnology $27: 1103-1105$

Canguilhem G (1971) Machine et organisme. In: La connaissance de la vie. Paris, Vrin (1st edn 1947)

Carlson R (2010) Biology is technology: the promise, peril and new business of engineering life. Harvard University Press, Cambridge, MA

Deplazes A (2009) Piecing together a puzzle. Embo Reports 10:428-432 Deplazes A, Ganguli-Mitra A, Biller-Andorno N (2009) The ethics of synthetic biology: outlining the agenda. In: Schmidt M, Kelle A, Ganguli-Mitra A, de Vriend H (eds) Synthetic biology: the technoscience and its societal consequences. Springer, Dordrecht, pp $65-80$ 
Dewey J (1939) Theory of valuation. University of Chicago Press, Chicago Dupuy J-P, Grinbaum A (2004) Ethics beyond prudence: towards a normative assessment of nanotechnology. European Workshop on Social and Economic Research on Nanotechnologies and Nanosciences. Brussels, April 14-15. http://Www.stage-research.net/STAGE/content/Nano.html. Accessed Feb 2013

Erickson B, Singh R, Winters P (2011) Synthetic biology: regulating industry uses of new biotechnologies. Science 333:1254-1255

ETC Group (2007) Extreme genetic engineering: an introduction to synthetic biology

http://www.etcgroup.org/en/materials/publications.html?pub_id=602 ETC Group (2008) Commodifying nature's last straw? Extreme genetic engineering and the post-petroleum sugar economy. http: //www.etcgroup.org/en/node/703?

ETC Group (2010) Synthia is alive...and breeding: panacea or Pandora's box? http://www.etcgroup.org/en/node/5142

European Group on Ethics in Science and New Technologies to the European Commission (2011) The ethics of synthetic biology, opinion no. 25. http://ec.europa.eu/. Accessed 11 Feb 2013

European Union (2010) Public survey on synthetic biology. ec.europa.eu/public_opinion/archives/ebs/ebs_341_en.pdf

Fioraso G (2012) Les enjeux de la biologie de synthèse. Report of L'office parlementaire des choix scientifiques et technologiques, Paris. http://senat.fr/notice-rapport/2011/r11-378-1-notice.html

Haraway D (1997) Modest_Witness@Second_Millennium. FemaleMan_Meets_OncoMouse: feminism and technoscience. Routledge, New York.

Hilgartner S (2012) Novel constitutions? New regimes of openness in synthetic biology. BioSocieties 7:188-207 
Jasanoff S (2003) Technologies of humility: itizen participation in governing science. Minerva 41:223-244

Kaebnick G (2009) Should moral objections to synthetic biology affect public policy. Nature Biotechnology 27:1106-1108

Kelle A (2009) Security issues related to synthetic biology. In: Schmidt M, Kelle A, Ganguli-Mitra A, de Vriend H (eds) Synthetic biology: the technoscience and its societal consequences. Springer, Dordrecht, pp 101-119

Kogge W, Richter M (2013) Synthetic biology and its alternatives: Descartes, Kant and the idea of engineering biological machines. In: Philosophical perspectives on synthetic biology, special issue of Studies in History and Philosophy of Biological and Biomedical Sciences $44: 181-189$

Kwok R (2010) Five hard truths for synthetic biology. Nature 463:288-290 Marlière P (2009) The farther, the safer: a manifesto for securely navigating synthetic species away from the old living world. Systems and Synthetic Biology 3:77-84

Maurer S (2009) Synthetic biology marketplace: screening out terrorists. The Hasting Center Report http: //www.thehastingscenter.org/Bioethicsforum/Post.aspx?id=4158\&bl ogid=140. Accessed 13 Feb 2013

Meyer M (2013) Aiming high, but investing little. Embo Reports 14, 2, doi: 10.1038 /embor.2012.19

Pei L, Gaisser S, Schmidt M (2011) Synthetic Biology in the view of European public funding organisations. Public Understanding of Science $1: 1-14$

Rabinow P (2004) Assembling ethics in an ecology of ignorance. Lecture given at the First Conference on Synthetic Biology, Massachusetts 
Institute of Technology, Cambridge, MA, 10-12 June 2004 .

http://openwetware.org/wiki/Synthetic_Biology:Synthetic_Biology_1.0

Rabinow P, Bennet G (2007) From bio-ethics to human practices. ARC Working Paper $\mathrm{N}^{\circ} 11$. http://anthropos-

lab.net/wp/publications/2007/08/workingpaperno1l.pdf. Accessed

February 2013

Rabinow P, Bennet G (2012) Designing human practices: an experiment with synthetic biology. University of Chicago Press, Chicago

Rodemeyer M (2009) New life, old bottles: regulating the first generation products of synthetic biology. Woodrow Wilson International Institute for Scholars, Washington DC http://www.synbioproject.org/library/publications/archive/synbio2/. Accessed February 2013

Royal Academy of Engineering (2009) Synthetic Biology, scope applications and implications. http://www.raeng.org.uk/synbio. Accessed February 2013

Schmidt M, De Lorenzo V (2012) Synthetic constructs in/for the environment: managing the interplay between natural and engineered biology. FEBS Letters 586:2199-2206

Schmidt M, Kelle A, Ganguli-Mitra A, de Vriend H (eds) (2009) Synthetic biology: the technoscience and its societal consequences. Springer, Dordrecht

Simondon G (1989) Du mode d'existence des objets techniques. Aubier, Paris (1st edn 1958)

Sutcliffe H (2011) A report on responsible research \& innovation. 
http://ec.europa.eu/research/science-

society/document_library/pdf_06/rri-report-hilary-sutcliffe_en.pdf.

Accessed December 2012

Vivagora (2009) Cycle de débats: la biologie synthétique en question

http://www.vivagora.fr/

Vivagora (2010) Synbio concerns: a bottom-up process driven by Vivagora

http://vivagora.org

Vinson V, Pennisi E (2011) The allure of synthetic biology. Science 333: 1235

Ruder WC, Lu T, Collins JJ (2011) Synthetic biology moving into the

clinic. Science 333:1248-1252

Williams B (1981) Moral luck. Cambridge University Press, Cambridge

Zhang JY, Marris C, Rose N (2011) The transnational governance of

synthetic biology: scientific uncertainty, cross-borderness and the

'art of governance.' BIOS Working Paper, London School of Economics

and Political Science, London

http://royalsociety.org/uploadedFiles/Royal_Society_Content/policy/publica

tions/2011/4294977685.pdf. Accessed 03.12.2012 <AQ: please give

complete reference: organization/author, year, title? Also, is

access date March 12 or December 3?>

$<$ END $>$

Corrections on Bernadette Bensaude Vincent

Ethical Perspectives on Synthetic Biology

Biological Theory Journal: 13752

Article: 137

Line 120 add (Kaebnick 2009 after 'the interests of society?'

Line 204 add (Rabinow Bennet 2007) after 'promised'

Line 288 add (Kelle 2009) after 'bioweapons'

Line 417 delete ; after '2009' + add a space after the parenthesis

Line 423 write 'denounce' instead of 'characterize'

Line 424 write 'which' instead of 'and'

Line 617 delete 'with'

Line 637 add 's' at the end of George (Georges) 
Line 671 add 'Accessed July 2013'

Line 674 add 'Accessed July 2013'

Line 683-85 delete the reference to Bontems

Lines 713, 716 and 718 add 'Accessed July 2013' to references ETC group 2007, 2008 and 2010

Line 726 add 'Accessed July 2013' to reference Fioraso

Line 743-744 delete the reference to Kwok

Line 789-90 delete the reference to Vinson and Pennisi

Line 792 add 'Accessed February 2013' to reference Vivagora 2009

Line 793-94 delete the reference Vivagora 2010

OK for Pei et al (2011) 